\title{
Nanomaterials Toxicity and Cell Death Modalities
}

\author{
Daniela De Stefano, ${ }^{1}$ Rosa Carnuccio, ${ }^{1}$ and Maria Chiara Maiuri ${ }^{1,2}$ \\ ${ }^{1}$ Dipartimento di Farmacologia Sperimentale, Facoltà di Scienze Biotecnologiche, Università degli Studi di Napoli Federico II, \\ Via D. Montesano 49, 80139 Napoli, Italy \\ ${ }^{2}$ INSERM U848, IGR, 39 Rue C. Desmoulins, 94805 Villejuif, France
}

Correspondence should be addressed to Maria Chiara Maiuri, mcmaiuri@unina.it

Received 10 September 2012; Accepted 7 November 2012

Academic Editor: Giuseppe De Rosa

Copyright ( $) 2012$ Daniela De Stefano et al. This is an open access article distributed under the Creative Commons Attribution License, which permits unrestricted use, distribution, and reproduction in any medium, provided the original work is properly cited.

In the last decade, the nanotechnology advancement has developed a plethora of novel and intriguing nanomaterial application in many sectors, including research and medicine. However, many risks have been highlighted in their use, particularly related to their unexpected toxicity in vitro and in vivo experimental models. This paper proposes an overview concerning the cell death modalities induced by the major nanomaterials.

\section{Introduction}

Nanotechnologies are emerging for important new applications of nanomaterials in various fields. Nanomaterials are defined as substances which have one or more external dimension in the nanoscale $(1-100 \mathrm{~nm})$. Nanomaterials, especially nanoparticles and nanofibres, show higher physical and chemical activities per unit weight. These properties explain their large application not only in industry but also in the scientific and medical researches. In fact, in these areas, the use of many kinds of manufactured nanoparticles products is in development, such as metal oxide nanoparticles (cerium dioxide, cupric oxide, titanium dioxide, zinc oxide, etc.), metal nanoparticles (gold, silver, platinum, palladium, etc.), C60 fullerenes nanocrystals, carbon nanotubes (CNTs), and quantum dots. Initially, the nanomaterials were believed to be biologically inert, but a growing literature has highlighted the toxicity and potential risks of their use. Extrapolations from the field of toxicology of particulate matter (less than $10 \mathrm{~nm}$ ) confirm that nanoparticles present a range of harmful effects $[1,2]$. In most cases, enhanced generation of reactive oxygen species (ROS), leading to oxidative stress which in turn may trigger proinflammatory responses, is assumed to be responsible for nanomaterials toxicity, although nonoxidative stress-related mechanisms have also been recently reported (see the extensive and interesting reviews [3-10]). However, despite intensive investigations, the understanding of nanomaterials-induced cellular damage remains to be clarified. The literature in the field suggests correlations between different physicochemical properties and the biological and toxicological effects of cells and tissues exposure to nanomaterials. First of all, nanomaterials are characterized by high specific surface area that correlates with high interfacial chemical and physical reactivity that, in turn, translates to biological reactivity [11]. The addition of different types of nanoparticles to various primary cell cultures or transformed cell lines may result in cell death or other toxicological outcomes, depending on the size of the nanomaterial. Quantum dots were reported to localize to different cellular compartment in a size-dependent manner [12]. Silica nanoparticles $(40-80 \mathrm{~nm})$ can enter into the nucleus and localize to distinct subnuclear domains in the nucleoplasm, whereas thin and coarse ones located exclusively in the cytoplasm [13]. Gold nanocluster $(1.4 \mathrm{~nm})$ intercalates within the major groove of DNA and is a potent inducer of cell death in human cancer cells [14]. Growing evidence suggests that the state of nanoparticles aggregation cannot be ignored; in fact, the toxicity may depend on the size of the agglomerate and not on the original nanoparticle size itself $[15,16]$. For example, in rats exposed by inhalation to $20 \mathrm{~nm}$ or $250 \mathrm{~nm}$ titanium dioxide $\left(\mathrm{TiO}_{2}\right)$ particles, the half-times for alveolar clearance of polystyrene test particles 


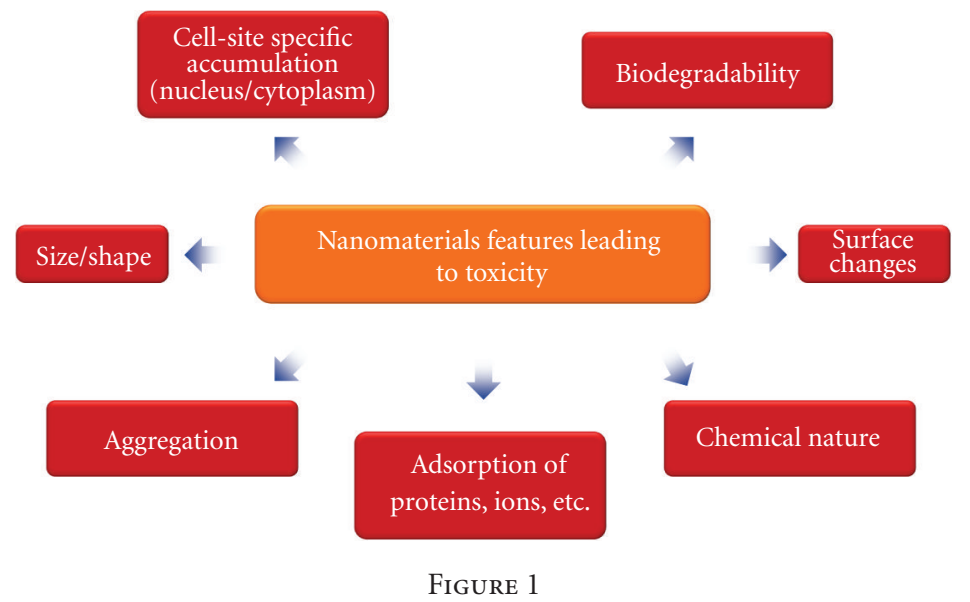

were proportional to the $\mathrm{TiO}_{2}$ particle surface area per million of macrophages $[17,18]$. Clearly, a surface impurity, resulting from air or water contaminants such as bacterial endotoxin, could contribute to the cellular responses induced by nanomaterials, in particular immunological responses [16]. The same consideration is true for residual materials (surfactants or transition metals) arising from the synthetic process $[6,19,20]$. Nevertheless, the adsorption ability and surface activity are also involved in cellular influences of nanomaterials. When dispersed in culture medium, some metal oxide nanoparticles and CNTs could adsorb proteins, often called "protein corona" such as serum albumin, or calcium, which could change the biological activity of nanomaterials. This adsorption could be particle size and time dependent. In these conditions, many nanoparticles form secondary particles, which are a complex of nanoparticles and medium components [21-26]. For example, adsorbed albumin on the CNT was involved in phagocytosis of the macrophage via scavenger receptor [27]. A surfaceengineered functionalization also may be linked with the biological nanomaterials activity, although in this item that is a wanted effect. Moreover, examples of dose-dependent toxicity also are evaluated $[6,28,29]$. As pointed out in a recent review [6], the degree of recognition and internalization of nanomaterials likely influences their distribution and may determine also their toxic potential. It has been reported that the number of internalized quantum dots (the intracellular dose) correlates with the toxicity in human breast cancer cell line [30]. Furthermore, the toxicity and cell death fate appear to correlate with the type of crystal structures [16, 31]. Finally, the nanomaterials degradability should also be taken into account (Figure 1). Nondegradable nanomaterials can accumulate into the cells and/or organs and exert damage effect as well as their degradation products [32-34]. However, it is not yet clear which of these parameters mainly influences the nanomaterials toxicity or if all of these features act together [35]. It is important to note that in the literature conflicting results are present. These are likely caused by variations in type, composition, size, shape, surface charge, and modifications of nanoparticles employed; use of various in vivo and in vitro models (the cell death mode may be also cell type dependent); experimental procedures (different methods to evaluate cell death; nanomaterials dose, concentrations and efficiency of cellular uptake, and time of exposure). This paper aims to give a critical overview concerning the different cell death modalities induced by nanomaterials.

Deregulated cell death is a common element of several human diseases, including cancer, stroke, and neurodegeneration, and the modulation of this cellular response can be an optimal target for an effective therapeutic strategy. Many cytotoxic agents are potent anticancer therapeutics, whereas cytoprotective compounds may be used to elude unwanted cell death in the context of stroke, myocardial infarction or neurodegenerative disorders $[36,37]$. The complex molecular mechanisms and signalling pathways that control cell death are increasingly becoming understood, and it is now clear that different cell death subroutines play a critical role in multiple diseases. In many instances, the modality by which cells die is crucial to the cell death achievement at the organism level. The Nomenclature Committee on Cell Death (NCCD) has recently formulated a novel systematic classification of cell death based on morphological characteristics, measurable biochemical features and functional considerations [38]. We will consider these definitions of cell death in order to summarize and organize the molecular mechanisms underlying the nanomaterials toxicity. We could not report all the studies, and we apologize for this; we will describe the most recently, accurate, and representative ones in term of the described molecular mechanisms.

\section{Nanomaterials and Apoptosis}

Apoptosis is a form of cellular suicide that can be classified into extrinsic and intrinsic apoptosis. Extrinsic apoptosis indicates the cell death, caspase dependent, stimulated by extracellular stress signals that are sensed and propagated by specific transmembrane receptors. Three major lethal signalling cascades have been reported: (i) death receptor signalling and activation of the caspase- 8 (or -10) and then caspase- 3 cascade; (ii) death receptor signalling and activation of the caspase- 8 then $\mathrm{BH} 3$-interacting domain 
death agonist (BID), mitochondrial outer membrane permeabilization (MOMP), caspase- 9 and caspase-3 pathways; and (iii) ligand deprivation-induced dependence receptor signalling followed by (direct or MOMP-dependent) activation of the caspase- 9 and after caspase- 3 cascade [38]. Intrinsic apoptosis can be triggered by a plethora of intracellular stress conditions, such as DNA damage, oxidative stress, and many others. It results from a bioenergetic and metabolic catastrophe coupled to multiple active executioner mechanisms. This process could be caspase-dependent or- independent and is mediated by MOMP associated with the generalized and irreversible dissipation of the mitochondrial transmembrane potential, release of mitochondrial intermembrane space proteins into the cytosol (and their possible relocalization to other subcellular compartments), and the respiratory chain inhibition [38]. Apoptosis plays a fundamental role in development and for maintenance of tissue homeostasis in the adult organism. In addition, impairment of apoptosis may contribute to tumour progression.

Nanomaterials are described as triggers of extrinsic and intrinsic apoptotic pathways; however, the oxidative stress paradigm of nanomaterials-induced cell death linked to intrinsic apoptotic network is by far the most accepted, in fact many in vitro studies have identified increased ROS generation as an initiating factor of toxicity in nanomaterials exposed cells $[3,6,7,10,39]$. Although it is well established that the mode of cell death depends on the severity of the cellular insult (which may, in turn, be linked to mitochondrial function and intracellular energy), it has been difficult to set up a comprehensive mechanism of nanomaterials cell death based on conflicting observations present in the literature. Furthermore, in most of the studies, the molecular mechanisms underlying cell death are not investigated. Finally, another problem is the nonhomogeneity of the studies, in terms of materials and experimental methods used, which makes it difficult to compare.

Sarkar and colleagues showed that the nano-copper induces intrinsic apoptotic cell death in mice kidney tissue (via the increase of ROS and reactive nitrogen species production, regulation of $\mathrm{Bcl}-2$ family protein expression, release of cytochrome $c$ from mitochondria to cytosol, and activation of caspase-3), but, in addition, they observed the activation of FAS, caspase- 8 , and tBID, suggesting also the involvement of extrinsic pathways [40]. The exposure to nano-copper dose-dependently caused oxidative stress and led to hepatic dysfunction in vivo. Nano-copper caused the reciprocal regulation of $\mathrm{Bcl}-2$ family proteins, disruption of mitochondrial membrane potential, release of cytochrome $c$, formation of apoptosome, and activation of caspase-3. These results indicate that nano-copper induces hepatic dysfunction and cell death via the oxidative stress-dependent signalling cascades and mitochondrial event [41].

Metallic nickel nanoparticles induced apoptotic cell death through an FAS/caspase-8/BID mediated, cytochrome $c$-independent pathway in mouse epidermal cells [42]. Nickel oxide nanoparticles excited in dose-dependent manner the increase of ROS production, lipid peroxidation, and caspase- 3 activation in human airway epithelial and breast cancer cells [43]. Moreover, nickel ferrite nanoparticles provoked apoptosis in human lung epithelial cells through ROS generation via upregulation of $\mathrm{p} 53$ and Bax as well as the activation of caspases cascade [44].

In vitro, silicon dioxide $\left(\mathrm{SiO}_{2}\right)$ nanoparticles increased ROS and RNS (reactive nitrogen species) production that, in turn, can induce the intrinsic apoptotic machinery [45]. Furthermore, Wang and collaborators showed that p53 plays a key role in silica-induced apoptosis in vitro (mouse preneoplastic epidermal cells and fibroblasts) and in vivo (p53 wild-type and deficient mice) [46].

$\mathrm{TiO}_{2}$ nanoparticles, sized less than $100 \mathrm{~nm}$, triggered apoptotic cell death through ROS-dependent upregulation of FAS and activation of Bax in normal human lung fibroblast and breast epithelial cell lines [47]. Moreover, it was also demonstrated that $\mathrm{TiO}_{2}$ nanoparticles induced apoptosis through the caspase-8/BID pathway in human bronchial epithelial cells and lymphocytes as well as in mouse preneoplastic epidermal cells $[48,49]$. Some reports indicated that $\mathrm{TiO}_{2}$ induced also lipid peroxidation, p53-mediated damage response, and caspase activation $[50,51]$. In contrast, there are also reports demonstrating that $\mathrm{TiO}_{2}$ nanoparticles did not induce oxidative stress on mouse macrophages [52] as well as did not shown cytotoxicity in human dermal fibroblasts and lung epithelial cells [31].

A number of studies have been published concerning the effects of CNTs on apoptosis. Multiwall carbon nanotubes (MWCNTs) induced an increase of ROS, cell cycle arrest, decrease in mitochondrial membrane potential, determining apoptosis in different in vitro models [53-56]. In contrast, another study reported that these nanotubes were nontoxic [57]. Accordingly, it has been observed that MWCNTs did not stimulate cell death in vitro after acute exposure and neither after the continuous presence of their low amounts for 6 months [58]. Instead, apoptotic macrophages have been observed in the airways of mice after inhalation of SWCNTs (single-walled carbon nanotubes) [6]. Accordingly, several studies in vivo suggest that the exposure to SWCNTs leads to the activation of specific apoptosis signalling pathways $[59,60]$. For more details, recent interesting reviews focus on the nanomaterials toxicity in vivo studies $[6,34]$.

Nanoparticles are frequently detected in lysosomes upon internalization, and a variety of nanomaterials have been associated with lysosomal dysfunction [61]. It has been established that lysosomal destabilization triggers the mitochondrial pathway of apoptosis $[62,63]$. Carbon nanotubes were shown to induce lysosomal membrane permeabilization and apoptotic cell death in murine macrophages and human fibroblasts $[64,65]$. Carbon black nanoparticles elicited intrinsic apoptosis in human bronchial epithelial cells with activation of Bax and release of cytochrome $c$ from mitochondria, whereas $\mathrm{TiO}_{2}$ nanoparticles induced apoptosis through lysosomal membrane destabilization and cathep$\sin B$ release, suggesting that the pathway of apoptosis differs depending on the nanomaterials chemical nature [66]. The lysosomal destabilization induced by $\mathrm{TiO}_{2}$ is also confirmed in mouse fibroblasts [67]. $\mathrm{SiO}_{2}$ and several cationic nanoparticles, such as cationic polystyrene nanospheres and cationic polyamidoamine (PAMAM) dendrimers, have also shown the same mode of action [68-70]. However, 
also the micromaterials are able to destabilize lysosomes, in fact silica microparticles have been demonstrated to induce apoptosis in mouse alveolar macrophages by this molecular mechanism [70]. A comparative study of nanoversus microscale gold particles demonstrated that nanoparticles present a higher potency in the induction of lysosomal membrane destabilization [71].

Chronic or unresolved endoplasmic reticulum (ER) stress can also cause apoptosis [72, 73]. Zhang and colleagues reported that the ER stress signalling is involved in silver nanoparticles-induced apoptosis in human Chang liver cells and Chinese hamster lung fibroblasts [74]. Using omic techniques and systems biology analysis, Tsai and collaborators demonstrated that upon ER stress, cellular responses, including ROS increase, mitochondrial cytochrome $c$ release, and mitochondria damage, chronologically occurred in the gold nanoparticles-treated human leukemia cells. This treatment did not induce apoptosis in the normal human peripheral blood mononuclear cells [75]. It has been shown that poly(ethylene glycol)-phosphoethanolamine (PEG-PE), an FDA-approved nonionic diblock copolymer widely used in drug delivery systems, accumulated in the ER and induced ER stress and apoptosis only in cancer cells (human adenocarcinomia alveolar basal epithelial), whereas it did not have effect in normal cells (secondary human lung fibroblasts and embryonic kidney cells) [76].

The predisposition of some nanoparticles to target mitochondria, ER, or lysosomes and initiate cell death could be used as a new cancer chemotherapy principle.

Interestingly, nanoparticles (polystyrene nanoparticles of 20-40 nm with two different surface chemistries, carboxylic acid, and amines) may also induce apoptosis in individual cells (differentiated human colorectal adenocarcinoma) that then propagates to other neighbouring cells through a "bystander killing effect." The authors of this study suggest that ingested nanoparticles represent a potential health risk due to their detrimental impact on the intestinal membrane by destroying their barrier protection capability over time [77].

Surely in this context, a common incentive to synchronize the studies and research efforts is needed. The understand why cancer cells and distinctive normal cells have different cell fates as a result of nanomaterials exposure, focusing on the underlying mechanisms, will allow a better prediction of the consequences of exposure to nanomaterials and a safer assessment of the risks (Figure 2).

\section{Nanomaterials and Mitotic Catastrophe}

Recently, Vitale and colleagues suggested a novel definition of mitotic catastrophe based on functional consideration [78]. They proposed to consider mitotic catastrophe not a "pure" cell death executioner pathway but as an oncosuppressive mechanism that is triggered by perturbations of the mitotic apparatus, is initiated during the $\mathrm{M}$ phase of the cell cycle, is paralleled by some degree of mitotic arrest, and induces cell death (apoptosis or necrosis) and senescence [78].

It has been reported that several nanomaterials, such as $\mathrm{SiO}_{2}, \mathrm{TiO}_{2}$, cobalt-chrome $(\mathrm{CoCr})$ metal particles, and carbon nanotubes, interact with structural elements of the cell, with an apparent binding to the cytoskeleton and in particular the tubulins $[79,80]$. In this setting, some evidence in vitro demonstrated that carbon nanotubes mimic or interfere with the cellular microtubule system, thereby disrupting the mitotic spindle apparatus and leading to aberrant cell division [81-83]. In particular, the perturbation of centrosomes and mitotic spindles dynamics caused by these nanoparticles results in monopolar, tripolar, and quadripolar divisions, that, in turn, could determinate aneuploidy [78], an event closely linked to the carcinogenesis. Tsaousi and collaborators found that alumina ceramic particles increase significantly in micronucleated binucleate cells [84], which is considered a morphological marker of mitotic catastrophe [78]. Interestingly, this increase was much greater after exposure of primary human fibroblasts to CoCr metal particles, suggesting that these nanoparticles are particularly efficient in affecting the mitotic machinery [84]. Apparently, the genotoxic effect of CoCr nanoparticles is size dependent. Indeed, $\mathrm{CoCr}$ nanoparticles induced more DNA damage than microsized ones in human fibroblasts (Figure 3). In fact, the mechanism of cell damage appears to be different after nano- or microparticles exposure. The enhanced oxidative DNA damage by the microparticles may result from a stronger ability of large particles to activate endogenous pathways of reactive oxygen species formation, for example, involving NADPH oxidases or mitochondrial activation. It also suggests that the observed genotoxic effect of the nanoparticles in the comet assay and the micronucleus assay (i.e., stronger aneugenic effect) is due to mechanisms other than oxidative DNA attack. A different mechanism of DNA damage by nanoparticles and microparticles is further suggested by measures of DNA damage from the comet and micronucleus assays. The comet assay revealed more damage in nanoparticle-exposed than in microparticle cells. In contrast, the micronucleus assay revealed slightly less centromere-negative micronuclei in nanoparticle exposed than in microparticle-exposed cells. This assay measures clastogenic, that is, double strand breakage events. Although some micronuclei in nanoparticle-exposed cells might not have been seen as a result of inhibition of cell division from greater cytotoxicity, these results point to a greater complexity of DNA damage caused by exposure to nanoparticles compared to microparticles [85]. A genotoxic effect has also described for silver nanoparticles that induced chromosomal aberrations, damage of metaphases, and aneuploidy in medaka (Oryzias latipes) cell line [86].

Further studies are needed to validate this dangerous potential effect of the nanomaterials. Obviously, close attention to safety issues will be required, also in the light of the potential interference between engineered nanomaterials and the environment.

\section{Nanomaterials and Autophagy or "Autophagic Cell Death"}

Autophagy is a highly conserved homeostatic process, involved in the recognition and turnover of damaged/aged 


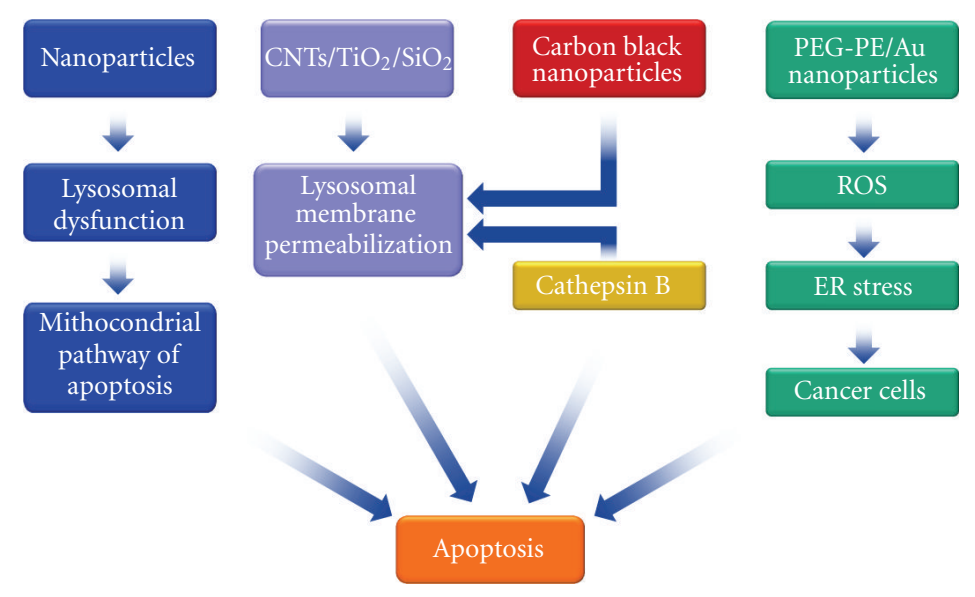

Figure 2

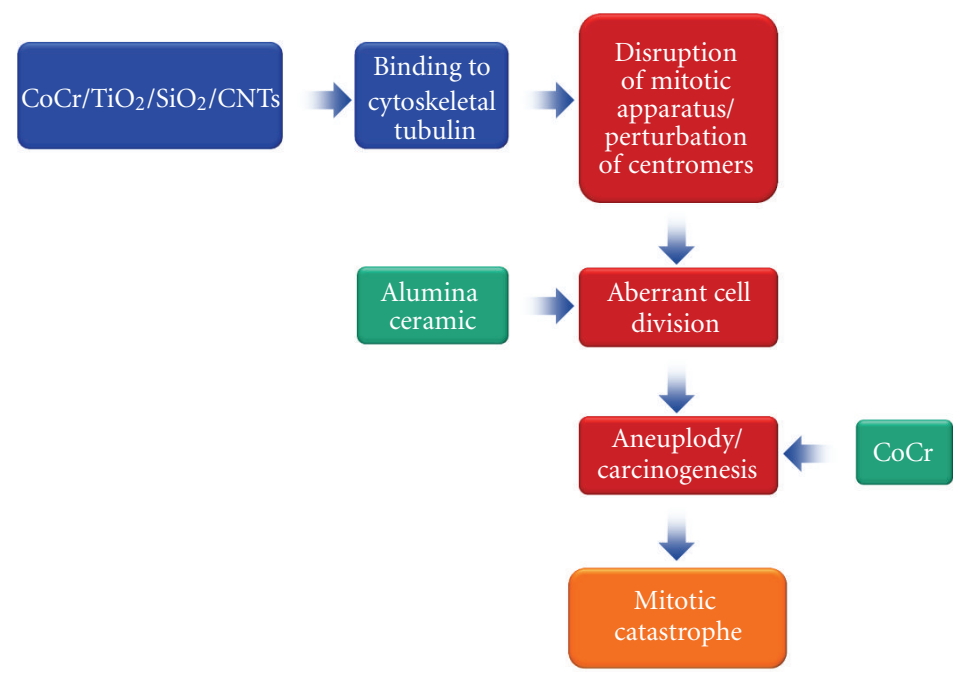

Figure 3

proteins and organelles. During autophagy, parts of the cytoplasm are sequestered within characteristic double- or multi-membraned autophagic vacuoles (named autophagosomes) and are finally delivered to lysosomes for bulk degradation. This process is dynamically regulated by ATG (Autophagy-related gene) gene family and is finely controlled by several signalling pathways [87]. Autophagy constitutes a cytoprotective response activated by cells in the challenge to cope with stress. In this setting, pharmacological or genetic inhibition of autophagy accelerates cell death. On the basis of morphological features, the term "autophagic cell death" has widely been used to indicate instances of cell death that are accompanied by a massive cytoplasmic vacuolization [38]. The expression "autophagic cell death" is highly prone to misinterpretation and hence must be used with caution, but, discussion this problem is beyond the scope of this paper, and an excellent paper concerning this subject has been published [88]. In any case, "autophagic cell death" is used to imply that autophagy would execute the cell demise. In the literature, it has been reported that several classes of nanomaterials induce elevated levels of autophagic vacuoles in different animals and human cell culture as well as in vivo models (masterfully summarized in two recent reviews $[10,61])$. Such nanomaterials include alumina, europium oxide, gadolinium oxide, gold, iron oxide, manganese, neodymium oxide, palladium, samarium oxide, silica, terbium oxide, titanium dioxide, ytterbium oxide, and yttrium oxide nanoparticles; nanoscale carbon black; fullerene and fullerene derivate; and protein-coated quantum dots. The induction of autophagy was evaluated using panoply of established methods, including the electron microscopy detection of autophagic vacuoles, the immunoblot detection of ATG expression level and/or LC3-I to LC3-II conversion (an established marker of autophagy activity) and/or cellular immunolabeling of punctate LC3-II in cytoplasmic vacuoles. These studies were performed in vivo but mainly in primary cells and/or cell lines from rat (alveolar macrophages, kidney, dopaminergic neuron, and glioma), mouse (macrophages and neuroblasts), porcine (kidney), and human (lung, oral, colon, breast, cervical and epithelial cancer cells as well as fibroblasts, peripheral blood mononuclear, and endothelial and mesenchymal stem cells). Nanomaterials may induce 
autophagy via an oxidative stress mechanism, such as accumulation of damaged proteins and subsequent endoplasmic reticulum or mitochondrial stress [39, 89-92] and altering gene/protein expression and/or regulation, and interfering with the kinase-mediated regulatory cascades [93-103]. The increase in autophagic vacuoles in response to nanomaterials may be an adaptive cellular response. There is evidence that autophagy can selectively compartmentalize nanomaterials. In fact, nanoparticles are commonly observed within the autophagosome compartment, suggesting that activation of autophagy is a targeted exertion to sequester and degrade these materials following entrance into the cytoplasm [104]. It is possible that the cells might perceive nanomaterials as an endosomal pathogen or an aggregation-prone protein (both commonly degraded by the autophagy machinery). Recent evidence supports ubiquitination of nanomaterials directly or indirectly via colocalization with ubiquitinated protein aggregates, suggesting that cells may indeed select nanomaterials for autophagy through a pathway similar to invading pathogens $[13,98,105]$. Additionally, ubiquitinated proteins accumulate concomitantly with nanomaterial-induced autophagic vacuoles [106].

It is important to underlie that nanoscale was a significant factor in eliciting the autophagic response. Autophagy was not induced by quantum dots that had a tendency to aggregate to microscale particles into the cells [107]. Nanoscale size dependence was also reported for neodymium oxide nanoparticle, with larger particles inducing less autophagy [108]. Apparently, modifications of the surface properties might be able to alter the autophagy-inducing activity of the nanomaterials. Cationic PAMAM dendrimers elicited autophagy more than anionic ones in vitro [94]. Carbon nanotubes with carboxylic acid group could induce autophagy, while those functionalized with poly-aminobenzene sulfonic acid and polyethylene glycol groups were not [100]. Recently, it has been published that a short synthetic peptide, RE1 , binds to lanthanide-based nanocrystals, forms a stable coating layer on the nanoparticles surface, and significantly abolishes their autophagy-inducing activity. Furthermore, the addition of an arginine-glycine-aspartic acid motif to RE-1 enhances autophagy induced by lanthanide-based nanocrystals [109].

It is also possible that nanomaterials cause a state of autophagic dysfunction, correlated with a blockade of autophagy flux, and this may be involved in their mechanism of toxicity $[110,111]$. Nanoparticles could give rise to autophagy dysfunction by overloading or directly inhibiting lysosomal enzymes or disrupting cytoskeleton-mediated vesicle trafficking, resulting in diminished autophagosomelysosome fusion [112]. Nanoparticles could also directly affect lysosomal stability by inducing lysosomal oxidative stress, alkalization, osmotic swelling, or causing detergentlike disruption of the lysosomal membrane (see the complete review of Stern and colleagues [61] about this subject). Disruption in autophagosome trafficking to the lysosome has been implicated in several human pathologies, including cancer development and progression as well as neurodegenerative diseases. As exposure to airborne pollution has been associated with Alzheimer and Parkinson-like pathologies, and nanoparticles are the primary particle number and surface area component of pollution-derived particulates, Stern and Johnson have recently postulated a relationship between nanoparticle-induced autophagy dysfunction and pollution-associated neurodegeneration [113].

Several studies have been suggested also that the nanomaterial-induced autophagy dysfunction is correlated with mitochondrial damage [102, 114-118].

In the majority of the studies, autophagosome accumulation induced by nanomaterials treatment was associated with cell death, unfortunately the possibility of autophagy inhibition was not often investigated (the block of autophagy flux and autophagy induction both can determinate autophagosome accumulation) [119], and the mechanism of nanomaterial-induced autophagy accumulation in many cases is unclear.

Interestingly, nanomaterials have been proposed also as tools to monitor autophagy $[120,121]$. In conclusion, a growing body of the literature indicates that nanomaterials impact the autophagy pathways, then the possible autophagic response should be always taken into consideration in the development of novel nanomaterials systems (Figure 4). Moreover, further studies should be performed to clarify the molecular mechanisms underlying the interaction between nanomaterials and the autophagy machinery as well as to expand the knowledge of the implications and biological significance of this modulation.

\section{Nanomaterials and Necrosis}

Necrosis was, for a long time, considered as an accidental form of cell death, but in recent years several studies clarified that this process is regulated and may play a role in multiple physiological and pathological settings [122]. Several triggers can induce regulated necrosis, including alkylating DNA damage, excitotoxins, and the ligation of death receptors [38, 122]. Indeed, when caspases are genetically or pharmacologically inhibited, RIP1 (receptor-interacting protein kinase 1) and its homolog RIP3 are not degraded and engage in physical and functional interactions that ultimately activate the execution of necrotic cell death $[38,122]$. It should be noted that RIP3-dependent and RIP1-independent cases of necrosis have been described, suggesting that there are several subprograms of regulated necrosis [38, 122-124]. In a genome-wide siRNA screen, Hitomi and colleagues elucidated the relationship between appotosis and necrosis pointing out that some components of the apoptotic pathway (e.g., the $\mathrm{BH} 3$-only protein $\mathrm{Bmf}$ ) are also crucial in the necrotic machinery [125]. Moreover, recent studies provide evidence that apoptosis and necrosis are closely linked [126128]. The term "necroptosis" has been used as a synonym of regulated necrosis, but it was originally introduced to indicate a specific case of necrosis, which is induced by death receptor ligation and can be inhibited by the RIP-1 targeting chemical necrostatin-1 [38, 122, 129].

In the literature, there are confused and inconsistent examples of necrosis induced by nanomaterials, because on one hand only the loss of cell viability is often evaluated without focalising into the cell death modalities and on 


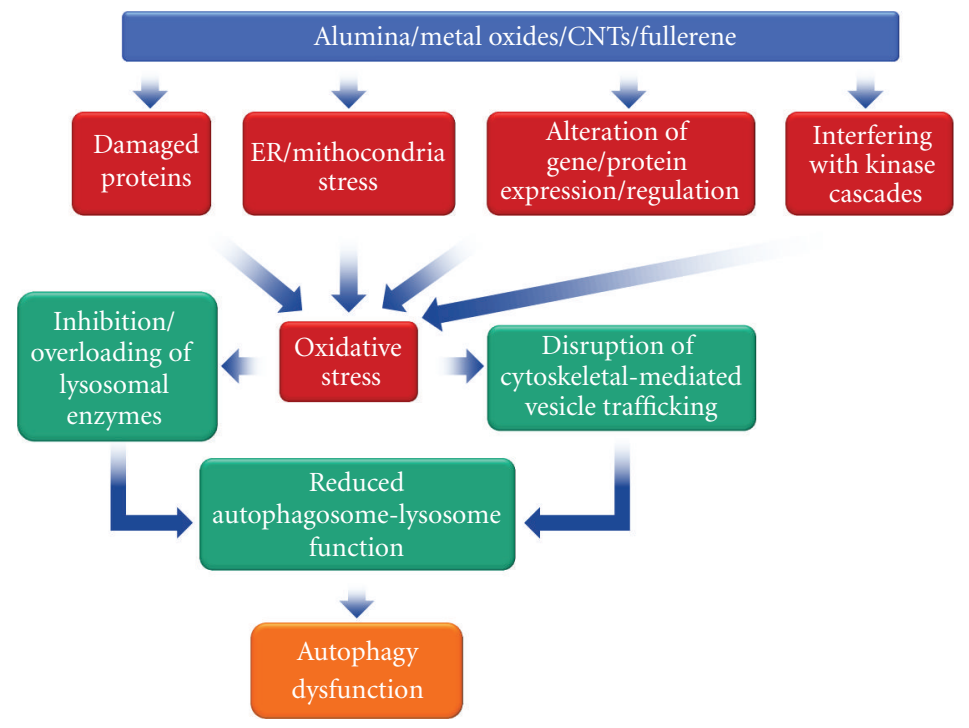

Figure 4

the other hand, there are no single discriminative biochemical markers available yet. Moreover, it should not be underestimated that the induction of apoptosis in cell culture is inevitably followed by secondary necrosis, and this could lead to a misinterpretation of results. However, a recent study demonstrated that water-soluble germanium nanoparticles with allylamine-conjugated surfaces $(4 \mathrm{~nm})$ induce necrotic cell death that is not inhibited by necrostatin-1 in Chinese hamster ovary cells [130]. Although the mechanisms of ligand and surface chemistry, surface charge, and crystallinitybased toxicity are complex, studies are beginning to elucidate certain surface functional groups and properties that can effectively alter biological responses. In fact, the crystal structure, with the different forms, of nanomaterials can dictate its cytotoxic potential. Braydich-Stolle and coworkers identify that both size and crystal structure (rutile, anatase, and amorphous) of $\mathrm{TiO}_{2}$ nanoparticles affect the mechanism of cell death in mouse keratinocyte cell line [131]. They found that $100 \%$ anatase $\mathrm{TiO}_{2}$ nanoparticles induced necrosis in size-independent manner, whereas the rutile $\mathrm{TiO}_{2}$ nanoparticles elicited apoptosis. Pan and collaborators investigated the size-dependent cytotoxicity exhibited by gold nanoparticles (stabilized with triphenylphosphine derivatives) in several human cell lines. All cell types internalised gold nanoparticles and showed signs of stress. Smaller particles $(<1.4 \mathrm{~nm})$ were more toxic than their larger equivalents. However, $1.4 \mathrm{~nm}$ nanoparticles cause predominantly rapid cell death by necrosis, while closely related particles $1.2 \mathrm{~nm}$ in diameter affect predominantly apoptosis [132, 133]. Besides, it has been reported that small $(10 \mathrm{~nm})$ silver nanoparticles had a greater ability to induce apoptosis than other-sized ones (50 and $100 \mathrm{~nm}$ ) in mouse osteoblastic cell line and induce necrosis in rat phaeochromocytoma cells [134]. The shape-dependent toxicity of polyaniline (PANI) nanomaterials with four different aspect ratios on human lung fibroblast cells was evaluated. The toxicity increased with decreasing aspect ratio of PANI nanomaterials; low aspect ratio PANI nanomaterials induced more necrosis than others [135]. Furthermore, the surface charge seems to be a major factor of how nanoparticles impact cellular processes. It has been demonstrated that charged gold nanoparticles induced cell death via apoptosis, whereas neutral nanoparticles caused necrosis [136]. Clearly, other parameters may influence the cell death modalities induced by nanomaterials, such as the dose or the time of exposure. Depending on the concentration, nano-C60 fullerene caused ROS-mediated necrosis (high dose), or ROS-independent autophagy (low dose) in rat and human glioma cell cultures [137]. The type of cell death induced by silver ions $\left(\mathrm{Ag}^{+}\right)$and silver nanoparticle coated with polyvinylpyrrolidone were also dependent on the dose and the exposure time, with $\mathrm{Ag}^{+}$being the most toxic in a human monocytic cell line [138]. The silver nanoparticles concentrations required to elicit apoptosis were found to be much lower than the concentrations required for necrosis in human fibrosarcoma, skin, and testicular embryonal carcinoma cells $[139,140]$. In conclusion, although the reports are often contradictory, the cell death appears roughly cell type, material composition, and concentration dependent. For instance, it has been reported that $\mathrm{TiO}_{2}(5-10 \mathrm{~nm})$, $\mathrm{SiO}_{2}(30 \mathrm{~nm}$ ), and MWCNTs (with different size: $<8 \mathrm{~nm}, 20-$ $30 \mathrm{~nm}$, and $>50 \mathrm{~nm}$, but same length $0.5-2 \mu \mathrm{m}$ ) induce cellspecific responses resulting in variable toxicity and subsequent cell fate in mouse fibroblasts and macrophages as well as telomerase-immortalized human bronchiolar epithelial cells. Precisely, the macrophages were very susceptible to nanomaterial toxicity, while fibroblasts are more resistant at all the treatments, whereas only the exposure of $\mathrm{SiO}_{2}$ and MWCNT $(<8 \mathrm{~nm})$ induce apoptosis in human bronchiolar epithelial cells. In the experimental conditions of this study, the investigated nanomaterials did not trigger necrosis [65]. In the same mouse macrophage cell line, it has been demonstrated that MWCNT (10-25 nm) and SWCNTs (1.2$1.5 \mathrm{~nm}$ ) induced necrosis in a concentration-dependent manner [141]. CNTs have been demonstrated to induce 
both necrosis and apoptosis in human fibroblasts [142]. In contrast, Cui and co-workers found that SWNTs upregulate apoptosis-associated genes in human embryo kidney cells [143], and Zhu and colleagues showed that MWCNTs induce apoptosis in mouse embryonic stem cells [144], while Pulskamp and collaborators assert that commercial CNTs do not induce necrosis or apoptosis in rat macrophages [145]. Recently, a multilevel approach, including different toxicity tests and gene-expression determinations, was used to evaluate the toxicity of two lanthanide-based luminescent nanoparticles, complexes with the chelating agent EDTA. The study revealed that these nanomaterials induced necrosis in human lymphoblasts and erythromyeloblastoid leukemia cell lines, while no toxicity was observed in human breast cancer cell line. Moreover, no in vivo effects have been observed. The comparative analysis of the nanomaterials and their separated components showed that the toxicity was mainly due to the presence of EDTA [146].

The knowledge advances concerning the molecular characterization of necrosis will make necessary more precise and accurate studies to confirm the ways in which nanomaterials might cause necrotic death.

\section{Nanomaterials and Pyroptosis}

Pyroptosis described the peculiar death of macrophages infected by Salmonella typhimurium [147]. Several other bacteria triggering this atypical cell death modality have been identified. Pyroptosis neither constitutes a macrophage-specific process nor a cell death subroutine that only results from bacterial infection. Pyroptotic cells can exhibit apoptotic and/or necrotic morphological features. The most distinctive biochemical feature of pyroptosis is the early caspase1 activation associated with the generation of pyrogenic mediators, such as Interleukin-1 $\beta$ (IL-1 $\beta$ ) [38].

Recently, it has been shown that the exposure of macrophages (both a mouse macrophage cell line and primary human alveolar macrophages) to carbon black nanoparticles resulted in inflammasome activation as defined by cleavage of caspase- 1 to its active form and downstream IL- $1 \beta$ release. The carbon black nanoparticles-induced cell death was identified as pyroptosis through the inhibition of caspase1 and pyroptosis by specific pharmacological inhibitors. The authors showed that, in this setting, $\mathrm{TiO}_{2}$ particles did not induce pyroptosis or significantly activate the inflammasome [148]. In contrast, it has been shown that nano$\mathrm{TiO}_{2}$ and nano-SiO 2 , but not nano- $\mathrm{ZnO}$ (zinc oxide) and carbon nanotubes, induced inflammasome activation but not cell death in murine bone marrow-derived macrophages and human macrophages cell line. Although the caspase- 1 cleavage and IL- $1 \beta$ release was induced, the inflammation caused by nanoparticles was largely caused by the biological effect of IL-1 $\alpha$ [149]. This apparent discrepancy could be explained considering the different concentration and kind of nanomaterials used in these studies; moreover, it is possible that different macrophages perform differently in response to nanomaterials. Future studies should address this issue. However, the identification of pyroptosis as a cellular response to carbon nanoparticles exposure is novel and relates to health impacts of carbon-based particulates.

\section{Conclusions and Perspectives}

The continued expansion of the nanotechnology field requires a thorough understanding of the potential mechanisms of nanomaterial toxicity for proper safety assessment and identification of exposure biomarkers. With increasing research into nanomaterial safety, details on the biological effects of nanomaterials have begun to emerge. The nanomaterials intrinsic toxicity has been attributed to their physicochemical characteristics, that is, their smallness and the remarkably large surface area per unit mass and high surface reactivity. In fact, their type, composition and modifications, size, shape, and surface charge should be considered. However, the complex death paradigms may also be explained by activation of different death pathways in a context-dependent manner. In vitro experiments could be influenced by a cell type-specific response, and ones in vivo could be affected by the animal species and the model used or by pharmacokinetic parameters (administration, distribution, metabolism, etc.). Moreover, the dose, concentrations, and the time of exposure of a nanomaterial employed are essential. In effect, the efficiency of cellular uptake of nanomaterials and the resultant intracellular concentration may determine the cytotoxic potential. Elucidating the molecular mechanisms by which nanosized particles induce activation of cell death signalling pathways will be critical for the development of prevention strategies to minimize the cytotoxicity of nanomaterials. Unfortunately, in the literature, there are many conflicting data; the most plausible reason is certainly the discrepancy of nanomaterials and experimental models engaged. Although some authors have recently alerted colleagues on these issues [3, 5, 8, 9, 150-152], it has not yet been put in place a guideline, generally accepted by the scientific community in the field, to address these matters. In fact, harmonization of protocols for material characterization and for cytotoxicity testing of nanomaterials is needed. In addition, parallel profiling of several classes of nanomaterials, combined with detailed characterization of their physicochemical properties, could provide a model for safety assessment of novel nanomaterials [153]. During the past decade, owing to major technological advances in the field of combinatorial chemistry in addition to the sequencing of an ever increasing number of genomes, highcontent chemical and genetic libraries have become available, raising the need for high-throughput screening (HTS) and high-content screening (HCS) approaches. In response to this demand, multiple conventional cell death detection methods have been adapted to HTS/HCS, and many novel HTS/HCS-amenable techniques have been developed [37, 154]. In the last years, several authors started to study the nanotoxicity with this tools and highlighted the potential of these approaches [9, 60, 75, 155-161]. An overall aim should identify HTS/HCS assays that can be used routinely to screen nanomaterials for interaction with the cell death modalities system. HTS/HCS may accelerated the analysis on a scale that commensurates with the rate of expansion 
of new nanomaterials but in any case is a first validation step, then it remains to confirm whether the same identified mechanisms in vitro are responsible for their in vivo toxicity. In conclusion, a multilevel-integrated uniform and consistent approach should contemplate for nanomaterial toxicity characterization.

In spite of the recent advances in our understanding of cell death mechanisms and associated signalling networks, much work remains to be done before we can fully elucidate the toxicological behaviour of the nanomaterials as well as understand their participation in the determination of cell fate. More and accurate results are needed for apoptosis, autophagy, and necrosis induction by nanomaterials; further studies are necessary to test if the novel strategic targets identified could be affected either directly or indirectly by nanomaterials. Moreover, no data are present in the literature concerning the nanomaterials exposure and other forms of cell death including anoikis, entosis, parthanatos, netosis, and cornification. For example, although numerous studies have been performed on keratinocytes, none of these has rated cornification, a cell death subroutine restricted to keratinocytes and functionally linked to the generation of the stratum corneum of the epidermis [38]. It will be of considerable interest to establish whether these various cell death modalities are associated with the intent of identifying a structure-activity relationship and delineating the mechanisms by which these interactions occur. In addition to the established paradigms of nanomaterials toxicity, the study of their interactions with the death signalling pathways could potentially have many important human pathological outcomes, including cancer, metabolic disorders, and neurodegenerative disorders.

\section{Abbreviations}

$\begin{array}{ll}\text { Ag }^{+}: & \text {Silver ions } \\ \text { ATG: } & \text { Autophagy-related gene } \\ \text { Bcl-2: } & \text { B-cell lymphoma } 2 \\ \text { BH3: } & \text { Bcl-2 homology domain } 3 \\ \text { BID: } & \text { BH3-interacting domain death agonist } \\ \text { Bmf: } & \text { Bcl-2-modifying factor } \\ \text { CNTs: } & \text { Carbon nanotubes } \\ \text { CoCr: } & \text { Cobalt-chrome } \\ \text { DNA: } & \text { Deoxyribonucleic acid } \\ \text { EDTA: } & \text { Ethylenediaminetetraacetic acid } \\ \text { ER: } & \text { Endoplasmic reticulum } \\ \text { FDA: } & \text { Food and Drug Administration } \\ \text { HCS: } & \text { High-content screening } \\ \text { HTS: } & \text { High-throughput screening } \\ \text { IL: } & \text { Interleukin } \\ \text { MOMP: } & \text { Mitochondrial outer membrane } \\ & \text { permeabilization } \\ \text { MWCNTs: } & \text { Multiwall carbon nanotubes } \\ \text { NADPH: } & \text { Nicotinamide adenine dinucleotide phosphate } \\ \text { NCCD: } & \text { Nomenclature Committee on Cell Death } \\ \text { PAMAM: } & \text { Cationic polyamidoamine } \\ \text { PANI: } & \text { Polyaniline } \\ \text { PEG-PE: } & \text { Poly(ethylene glycol)-phosphoethanolamine } \\ \text { RIP: } & \text { Receptor-interacting protein kinase } \\ & \end{array}$

RNA: Ribonucleic acid

RNS: $\quad$ Reactive nitrogen species

ROS: $\quad$ Reactive oxygen species

$\mathrm{SiO}_{2}$ : $\quad$ Silicon dioxide

siRNA: Small interfering RNA

SWCNTs: Single-walled carbon nanotubes

tBID: $\quad$ Truncated BID

$\mathrm{TiO}_{2}$ : Titanium dioxide

ZnO: $\quad$ Zinc oxide.

\section{Conflict of Interests}

The authors declare that they have no conflict of interests.

\section{Acknowledgment}

This work is supported by the Italian Ministry of the University and Scientific Research.

\section{References}

[1] G. Oberdörster, "Nanotoxicology: in vitro-in vivo dosimetry," Health Perspect, vol. 120, no. 1, p. 13, 2012.

[2] S. Gangwal, J. Brown, A. Wang, K.A. Houck, and D.J. Dix, "Informing selection of nanomaterial concentrations for ToxCast in vitro testing based on occupational exposure potential," Health Perspect, vol. 119, no. 11, pp. 1539-1546, 2011.

[3] A. Nel, T. Xia, L. Mädler, and N. Li, “Toxic potential of materials at the nanolevel," Science, vol. 311, no. 5761, pp. 622627, 2006.

[4] T. Xia, N. Li, and A. E. Nel, "Potential health impact of nanoparticles," Annual Review of Public Health, vol. 30, pp. 137150, 2009.

[5] E. J. Petersen and B. C. Nelson, "Mechanisms and measurements of nanomaterial-induced oxidative damage to DNA," Analytical and Bioanalytical Chemistry, vol. 398, no. 2, pp. 613-650, 2010.

[6] A. A. Shvedova, V. E. Kagan, and B. Fadeel, "Close encounters of the small kind: adverse effects of man-made materials interfacing with the nano-cosmos of biological systems," Annual Review of Pharmacology and Toxicology, vol. 50, pp. 63-88, 2010.

[7] S. Orrenius, P. Nicotera, and B. Zhivotovsky, "Cell death mechanisms and their implications in toxicology," Toxicological Sciences, vol. 119, no. 1, pp. 3-19, 2011.

[8] M. Horie, H. Kato, K. Fujita, S. Endoh, and H. Iwahashi, "In vitro evaluation of cellular response induced by manufactured nanoparticles," Chemical Research in Toxicology, vol. 25, no. 3, pp. 605-619, 2012.

[9] A. A. Shvedova, A. Pietroiusti, B. Fadeel, and V. E. Kagan, "Mechanisms of carbon nanotube-induced toxicity: focus on oxidative stress," Toxicology and Applied Pharmacology, vol. 261, no. 2, pp. 121-133, 2012.

[10] F. T. Andón and B. Fadeel, "Programmed cell death: molecular mechanisms and implications for safety assessment of nanomaterials," Accounts of Chemical Research. In press.

[11] C. F. Jones and D. W. Grainger, "In vitro assessments of nanomaterial toxicity," Advanced Drug Delivery Reviews, vol. 61, no. 6, pp. 438-456, 2009. 
[12] I. Nabiev, S. Mitchell, A. Davies et al., "Nonfunctionalized nanocrystals can exploit a cell's active transport machinery delivering them to specific nuclear and cytoplasmic compartments," Nano Letters, vol. 7, no. 11, pp. 3452-3461, 2007.

[13] M. Chen and A. Von Mikecz, "Formation of nucleoplasmic protein aggregates impairs nuclear function in response to $\mathrm{SiO}_{2}$ nanoparticles," Experimental Cell Research, vol. 305, no. 1, pp. 51-62, 2005.

[14] M. Tsoli, H. Kuhn, W. Brandau, H. Esche, and G. Schmid, "Cellular uptake and toxicity of Au55 clusters," Small, vol. 1, no. 8-9, pp. 841-844, 2005.

[15] A. M. Schrand, L. K. Braydich-Stolle, J. J. Schlager, L. Dai, and S. M. Hussain, "Can silver nanoparticles be useful as potential biological labels?” Nanotechnology, vol. 19, no. 23, Article ID 235104, 2008.

[16] S. M. Hussain, L. K. Braydich-Stolle, A. M. Schrand et al., "Toxicity evaluation for safe use of nanomaterials: recent achievements and technical challenges," Advanced Materials, vol. 21, no. 16, pp. 1549-1559, 2009.

[17] G. Oberdorster, J. Ferin, and B. E. Lehnert, "Correlation between particle size, in vivo particle persistence, and lung injury," Environmental Health Perspectives, vol. 102, no. 5, pp. 173-179, 1994.

[18] C. Monteiller, L. Tran, W. MacNee et al., "The proinflammatory effects of low-toxicity low-solubility particles, nanoparticles and fine particles, on epithelial cells in vitro: the role of surface area," Occupational and Environmental Medicine, vol. 64, no. 9, pp. 609-615, 2007.

[19] E. E. Connor, J. Mwamuka, A. Gole, C. J. Murphy, and M. D. Wyatt, "Gold nanoparticles are taken up by human cells but do not cause acute cytotoxicity," Small, vol. 1, no. 3, pp. 325-327, 2005.

[20] V. E. Kagan, Y. Y. Tyurina, V. A. Tyurin et al., "Direct and indirect effects of single walled carbon nanotubes on RAW 264.7 macrophages: role of iron," Toxicology Letters, vol. 165, no. 1, pp. 88-100, 2006.

[21] T. Cedervall, I. Lynch, S. Lindman et al., "Understanding the nanoparticle-protein corona using methods to quntify exchange rates and affinities of proteins for nanoparticles," Proceedings of the National Academy of Sciences of the United States of America, vol. 104, no. 7, pp. 2050-2055, 2007.

[22] M. Horie, K. Nishio, K. Fujita et al., "Protein adsorption of ultrafine metal oxide and its influence on cytotoxicity toward cultured cells," Chemical Research in Toxicology, vol. 22, no. 3, pp. 543-553, 2009.

[23] M. S. Ehrenberg, A. E. Friedman, J. N. Finkelstein, G. Oberdörster, and J. L. McGrath, "The influence of protein adsorption on nanoparticle association with cultured endothelial cells," Biomaterials, vol. 30, no. 4, pp. 603-610, 2009.

[24] M. Horie, K. Nishio, H. Kato et al., "Cellular responses induced by cerium oxide nanoparticles: induction of intracellular calcium level and oxidative stress on culture cells," The Journal of Biochemistry, vol. 150, no. 4, pp. 461-471, 2011.

[25] M. Lundqvist, J. Stigler, T. Cedervall et al., "The evolution of the protein corona around nanoparticles: a test study," ACS Nano, vol. 5, no. 9, pp. 7503-7509, 2011.

[26] M. P. Monopoli, D. Walczyk, A. Campbell et al., "PhysicalChemical aspects of protein corona: relevance to in vitro and in vivo biological impacts of nanoparticles," Journal of the American Chemical Society, vol. 133, no. 8, pp. 2525-2534, 2011.
[27] D. Dutta, S. K. Sundaram, J. G. Teeguarden et al., "Adsorbed proteins influence the biological activity and molecular targeting of nanomaterials," Toxicological Sciences, vol. 100, no. 1, pp. 303-315, 2007.

[28] N. Lewinski, V. Colvin, and R. Drezek, "Cytotoxicity of nanopartides," Small, vol. 4, no. 1, pp. 26-49, 2008.

[29] S. T. Stern and S. E. McNeil, "Nanotechnology safety concerns revisited," Toxicological Sciences, vol. 101, no. 1, pp. 421, 2008.

[30] E. Chang, N. Thekkek, W. W. Yu, V. L. Colvin, and R. Drezek, "Evaluation of quantum dot cytotoxicity based on intracellular uptake," Small, vol. 2, no. 12, pp. 1412-1417, 2006.

[31] C. M. Sayes, R. Wahi, P. A. Kurian et al., "Correlating nanoscale titania structure with toxicity: a cytotoxicity and inflammatory response study with human dermal fibroblasts and human lung epithelial cells," Toxicological Sciences, vol. 92, no. 1, pp. 174-185, 2006.

[32] G. Jones and P. M. Brooks, "Injectable gold compounds: an overview," British Journal of Rheumatology, vol. 35, no. 11, pp. 1154-1158, 1996.

[33] M. L. Schipper, N. Nakayama-Ratchford, C. R. Davis et al., "A pilot toxicology study of single-walled carbon nanotubes in a small sample of mice," Nature Nanotechnology, vol. 3, no. 4, pp. 216-221, 2008.

[34] K. L. Aillon, Y. Xie, N. El-Gendy, C. J. Berkland, and M. L. Forrest, "Effects of nanomaterial physicochemical properties on in vivo toxicity," Advanced Drug Delivery Reviews, vol. 61, no. 6, pp. 457-466, 2009.

[35] C. Buzea, I. I. Pacheco, and K. Robbie, "Nanomaterials and nanoparticles: sources and toxicity," Biointerphases, vol. 2, no. 4, pp. MR17-MR71, 2007.

[36] J. M. Brown and L. D. Attardi, "The role of apoptosis in cancer development and treatment response," Nature Reviews Cancer, vol. 5, no. 3, pp. 231-237, 2005.

[37] O. Kepp, L. Galluzzi, M. Lipinski, J. Yuan, and G. Kroemer, "Cell death assays for drug discovery," Nature Reviews Drug Discovery, vol. 10, no. 3, pp. 221-237, 2011.

[38] L. Galluzzi, I. Vitale, J. M. Abrams et al., "Molecular definitions of cell death subroutines: recommendations of the Nomenclature Committee on cell death," Cell Death \& Differentiation, vol. 19, no. 1, pp. 107-120, 2012.

[39] N. Li, T. Xia, and A. E. Nel, "The role of oxidative stress in ambient particulate matter-induced lung diseases and its implications in the toxicity of engineered nanoparticles," Free Radical Biology and Medicine, vol. 44, no. 9, pp. 1689-1699, 2008.

[40] A. Sarkar, J. Das, P. Manna, and P. C. Sil, "Nano-copper induces oxidative stress and apoptosis in kidney via both extrinsic and intrinsic pathways," Toxicology, vol. 290, no. 2-3, pp. 208-217, 2011.

[41] P. Manna, M. Ghosh, J. Ghosh, J. Das, and P. C. Sil, “Contribution of nano-copper particles to in vivo liver dysfunction and cellular damage: role of IêBá/NF-êB, MAPKs and mitochondrial signal," Nanotoxicology, vol. 6, no. 1, pp. 1-21, 2012.

[42] J. Zhao, L. Bowman, X. Zhang et al., "Metallic nickel nanoand fine particles induce JB6 cell apoptosis through a caspase-8/AIF mediated cytochrome c-independent pathway," Journal of Nanobiotechnology, vol. 7, article 2, 2009.

[43] M. A. Siddiqui, M. Ahamed, J. Ahmad et al., "Nickel oxide nanoparticles induce cytotoxicity, oxidative stress and apoptosis in cultured human cells that is abrogated by the dietary 
antioxidant curcumin," Food and Chemical Toxicology, vol. 50, no. 3-4, pp. 641-647, 2012.

[44] M. Ahamed, M. J. Akhtar, M. A. Siddiqui et al., "Oxidative stress mediated apoptosis induced by nickel ferrite nanoparticles in cultured A549 cells," Toxicology, vol. 283, no. 2-3, pp. 101-108, 2011.

[45] B. Fubini and A. Hubbard, "Reactive oxygen species (ROS) and reactive nitrogen species (RNS) generation by silica in inflammation and fibrosis," Free Radical Biology and Medicine, vol. 34, no. 12, pp. 1507-1516, 2003.

[46] L. Wang, L. Bowman, Y. Lu et al., "Essential role of p53 in silica-induced apoptosis," American Journal of Physiology, vol. 288, no. 3, pp. L488-L496, 2005.

[47] K. C. Yoo, C. H. Yoon, D. Kwon et al., "Titanium dioxide induces apoptotic cell death through reactive oxygen speciesmediated Fas upregulation and Bax activation," International Journal of Nanomedicine, vol. 7, pp. 1203-1214, 2012.

[48] S. J. Kang, B. M. Kim, S. H. Hong, and H. W. Chung, "Titanium dioxide nanoparticles induce apoptosis through the JNK/p38-caspase-8-Bid pathway in phytohemagglutininstimulated human lymphocytes," Biochemical and Biophysical Research Communications, vol. 386, no. 4, pp. 682-687, 2009.

[49] Y. Shi, F. Wang, J. He, S. Yadav, and H. Wang, "Titanium dioxide nanoparticles cause apoptosis in BEAS-2B cells through the caspase 8/t-Bid-independent mitochondrial pathway," Toxicology Letters, vol. 196, no. 1, pp. 21-27, 2010.

[50] S. J. Kang, B. M. Kim, Y. J. Lee, and H. W. Chung, "Titanium dioxide nanoparticles trigger p53-mediated damage response in peripheral blood lymphocytes," Environmental and Molecular Mutagenesis, vol. 49, no. 5, pp. 399-405, 2008.

[51] E. J. Park, J. Yi, K. H. Chung, D. Y. Ryu, J. Choi, and K. Park, "Oxidative stress and apoptosis induced by titanium dioxide nanoparticles in cultured BEAS-2B cells," Toxicology Letters, vol. 180, no. 3, pp. 222-229, 2008.

[52] T. Xia, M. Kovochich, J. Brant et al., "Comparison of the abilities of ambient and manufactured nanoparticles to induce cellular toxicity according to an oxidative stress paradigm," Nano Letters, vol. 6, no. 8, pp. 1794-1807, 2006.

[53] L. Ding, J. Stilwell, T. Zhang et al., "Molecular characterization of the cytotoxic mechanism of multiwall carbon nanotubes and nano-onions on human skin fibroblast," Nano Letters, vol. 5, no. 12, pp. 2448-2464, 2005.

[54] M. Bottini, S. Bruckner, K. Nika et al., "Multi-walled carbon nanotubes induce T lymphocyte apoptosis," Toxicology Letters, vol. 160, no. 2, pp. 121-126, 2006.

[55] C. Grabinski, S. Hussain, K. Lafdi, L. Braydich-Stolle, and J. Schlager, "Effect of particle dimension on biocompatibility of carbon nanomaterials," Carbon, vol. 45, no. 14, pp. 28282835, 2007.

[56] R. K. Srivastava, A. B. Pant, M. P. Kashyap et al., "Multiwalled carbon nanotubes induce oxidative stress and apoptosis in human lung cancer cell line-A549," Nanotoxicology, vol. 5, no. 2, pp. 195-207, 2011.

[57] J. Chłopek, B. Czajkowska, B. Szaraniec, E. Frackowiak, K. Szostak, and F. Béguin, "In vitro studies of carbon nanotubes biocompatibility," Carbon, vol. 44, no. 6, pp. 1106-1111, 2006.

[58] T. Thurnherr, C. Brandenberger, K. Fischer et al., "A comparison of acute and long-term effects of industrial multiwalled carbon nanotubes on human lung and immune cells in vitro," Toxicology Letters, vol. 200, no. 3, pp. 176-186, 2011.

[59] L. Wang, S. Luanpitpong, V. Castranova et al., "Carbon nanotubes induce malignant transformation and tumorigenesis of human lung epithelial cells," Nano Letters, vol. 11, no. 7, pp. 2796-2803, 2011.

[60] Y. Y. Tyurina, E. R. Kisin, A. Murray et al., "Global phospholipidomics analysis reveals selective pulmonary peroxidation profiles upon inhalation of single-walled carbon nanotubes," ACS Nano, vol. 5, no. 9, pp. 7342-7353, 2011.

[61] S. T. Stern, P. P. Adiseshaiah, and R. M. Crist, "Autophagy and lysosomal dysfunction as emerging mechanisms of nanomaterial toxicity," Particle and Fibre Toxicology, vol. 9, no. 1, p. 20, 2012.

[62] M. H. Èesen, K. Pegan, A. Spes, and B. Turk, "Lysosomal pathways to cell death and their therapeutic applications," Experimental Cell Research, vol. 318, no. 11, pp. 1245-1251, 2012.

[63] U. Repnik, V. Stoka, V. Turk, and B. Turk, "Lysosomes and lysosomal cathepsins in cell death," Biochimica et Biophysica Acta, vol. 1824, no. 1, pp. 22-33, 2012.

[64] Y. Tahara, M. Nakamura, M. Yang, M. Zhang, S. Iijima, and M. Yudasaka, "Lysosomal membrane destabilization induced by high accumulation of single-walled carbon nanohorns in murine macrophage RAW 264.7," Biomaterials, vol. 33, no. 9, pp. 2762-2769, 2012.

[65] S. K. Sohaebuddin, P. T. Thevenot, D. Baker, J. W. Eaton, and L. Tang, "Nanomaterial cytotoxicity is composition, size, and cell type dependent," Part. Fibre Toxicol, vol. 21, no. 7, p. 22, 2010.

[66] S. Hussain, L. C. J. Thomassen, I. Ferecatu et al., "Carbon black and titanium dioxide nanoparticles elicit distinct apoptotic pathways in bronchial epithelial cells," Particle and Fibre Toxicology, vol. 7, article 10, 2010.

[67] C. Y. Jin, B. S. Zhu, X. F. Wang, and Q. H. Lu, "Cytotoxicity of titanium dioxide nanoparticles in mouse fibroblast cells," Chemical Research in Toxicology, vol. 21, no. 9, pp. 18711877, 2008.

[68] T. Xia, M. Kovochich, M. Liong, J. I. Zink, and A. E. Nel, "Cationic polystyrene nanosphere toxicity depends on cellspecific endocytic and mitochondrial injury pathways," ACS Nano, vol. 2, no. 1, pp. 85-96, 2008.

[69] T. P. Thomas, I. Majoros, A. Kotlyar, D. Mullen, M. M. Banaszak Holl, and J. R. Baker, "Cationic poly(amidoamine) dendrimer induces lysosomal apoptotic pathway at therapeutically relevant concentrations," Biomacromolecules, vol. 10, no. 12, pp. 3207-3214, 2009.

[70] M. S. Thibodeau, C. Giardina, D. A. Knecht, J. Helble, and A. K. Hubbard, "Silica-induced apoptosis in mouse alveolar macrophages is initiated by lysosomal enzyme activity," Toxicological Sciences, vol. 80, no. 1, pp. 34-48, 2004.

[71] S. Tedesco, H. Doyle, J. Blasco, G. Redmond, and D. Sheehan, "Oxidative stress and toxicity of gold nanoparticles in Mytilus edulis," Aquatic Toxicology, vol. 100, no. 2, pp. 178-186, 2010.

[72] I. Tabas and D. Ron, "Integrating the mechanisms of apoptosis induced by endoplasmic reticulum stress," Nature Cell Biology, vol. 13, no. 3, pp. 184-190, 2011.

[73] A. M. Gorman, S. J. Healy, R. Jäger, and A. Samali, "Stress management at the ER: regulators of ER stress-induced apoptosis," Pharmacology \& Therapeutics, vol. 134, no. 3, pp. 306-316, 2012.

[74] R. Zhang, M. J. Piao, K. C. Kim et al., "Endoplasmic reticulum stress signaling is involved in silver nanoparticles-induced apoptosis," The International Journal of Biochemistry \& Cell Biology, vol. 44, no. 1, pp. 224-232, 2012.

[75] Y. Y. Tsai, Y. H. Huang, Y. L. Chao et al., "Identification of the nanogold particle-induced endoplasmic reticulum stress 
by omic techniques and systems biology analysis," ACS Nano, vol. 5, no. 12, pp. 9354-9369, 2011.

[76] J. Wang, X. Fang, and W. Liang, "Pegylated phospholipid micelles induce endoplasmic reticulum-dependent apoptosis of cancer cells but not normal cells," ACS Nano, vol. 6, no. 6, pp. 5018-5030, 2012.

[77] A. Thubagere and B. M. Reinhard, "Nanoparticle-induced apoptosis ropagates through hydrogen-peroxide-mediated bystander killing: insights from a human intestinal epithelium in vitro model," ACS Nano, vol. 4, no. 7, pp. 3611-3622, 2010.

[78] I. Vitale, L. Galluzzi, M. Castedo, and G. Kroemer, "Mitotic catastrophe: a mechanism for avoiding genomic instability," Nature Reviews. Molecular Cell Biology, vol. 12, no. 6, pp. 385-392, 2011.

[79] A. E. Porter, M. Gass, K. Muller, J. N. Skepper, P. A. Midgley, and M. Welland, "Direct imaging of single-walled carbon nanotubes in cells," Nature Nanotechnology, vol. 2, no. 11, pp. 713-717, 2007.

[80] L. Gonzalez, I. Decordier, and M. Kirsch-Volders, "Induction of chromosome malsegregation by nanomaterials," Biochemical Society Transactions, vol. 38, no. 6, pp. 1691-1697, 2010.

[81] L. M. Sargent, A. A. Shvedova, A. F. Hubbs et al., "Induction of aneuploidy by single-walled carbon nanotubes," Environmental and Molecular Mutagenesis, vol. 50, no. 8, pp. 708$717,2009$.

[82] L. M. Sargent, S. H. Reynolds, and V. Castranova, "Potential pulmonary effects of engineered carbon nanotubes: in vitro genotoxic effects," Nanotoxicology, vol. 4, no. 4, pp. 396-408, 2010.

[83] L. M. Sargent, A. F. Hubbs, S. H. Young et al., "Single-walled carbon nanotube-induced mitotic disruption," Mutation Research, vol. 745, no. 1-2, pp. 28-37, 2012.

[84] A. Tsaousi, E. Jones, and C. P. Case, "The in vitro genotoxicity of orthopaedic ceramic $\left(\mathrm{Al}_{2} \mathrm{O}_{3}\right)$ and metal ( $\mathrm{CoCr}$ alloy) particles," Mutation Research, vol. 697, no. 1-2, pp. 1-9, 2010.

[85] I. Papageorgiou, C. Brown, R. Schins et al., "The effect of nano- and micron-sized particles of cobalt-chromium alloy on human fibroblasts in vitro," Biomaterials, vol. 28, no. 19, pp. 2946-2958, 2007.

[86] J. P. Wise, B. C. Goodale, S. S. Wise et al., "Silver nanospheres are cytotoxic and genotoxic to fish cells," Aquatic Toxicology, vol. 97, no. 1, pp. 34-41, 2010.

[87] D. J. Klionsky, “The molecular machinery of autophagy and its role in physiology and disease," Seminars in Cell and Developmental Biology, vol. 21, no. 7, p. 663, 2010.

[88] G. Kroemer and B. Levine, "Autophagic cell death: the story of a misnomer," Nature Reviews Molecular Cell Biology, vol. 9, no. 12, pp. 1004-1010, 2008.

[89] Q. Zhang, W. Yang, N. Man et al., "Autophagy-mediated chemosensitization in cancer cells by fullerene C60 nanocrystal," Autophagy, vol. 5, no. 8, pp. 1107-1117, 2009.

[90] J. J. Li, D. Hartono, C. N. Ong, B. H. Bay, and L. Y. L. Yung, "Autophagy and oxidative stress associated with gold nanoparticles," Biomaterials, vol. 31, no. 23, pp. 5996-6003, 2010.

[91] B. Halamoda Kenzaoui, C. Chapuis Bernasconi, S. GuneyAyra, and L. Juillerat-Jeanneret, "Induction of oxidative stress, lysosome activation and autophagy by nanoparticles in human brain-derived endothelial cells," Biochemical Journal, vol. 441, no. 3, pp. 813-821, 2012.

[92] Z. M. Markovic, B. Z. Ristic, K. M. Arsikin et al., "Graphene quantum dots as autophagy-inducing photodynamic agents," Biomaterials, vol. 33, no. 29, pp. 7084-7092, 2012.
[93] S. T. Stern, B. S. Zolnik, C. B. McLeland, J. Clogston, J. Zheng, and S. E. McNeil, "Induction of autophagy in porcine kidney cells by quantum dots: a common cellular response to nanomaterials?" Toxicological Sciences, vol. 106, no. 1, pp. 140-152, 2008.

[94] C. Li, H. Liu, Y. Sun et al., "PAMAM nanoparticles promote acute lung injury by inducing autophagic cell death through the Akt-TSC2-mTOR signaling pathway," Journal of Molecular Cell Biology, vol. 1, no. 1, pp. 37-45, 2009.

[95] L. Yu, Y. Lu, N. Man, S. H. Yu, and L. P. Wen, "Rare earth oxide nanocrystals induce autophagy in hela cells," Small, vol. 5, no. 24, pp. 2784-2787, 2009.

[96] N. Man, L. Yu, S. H. Yu, and L. P. Wen, "Rare earth oxide nanocrystals as a new class of autophagy inducers," Autophagy, vol. 6, no. 2, pp. 310-311, 2010.

[97] C. M. Lee, S. T. Huang, S. H. Huang et al., "C60 fullerenepentoxifylline dyad nanoparticles enhance autophagy to avoid cytotoxic effects caused by the $\beta$-amyloid peptide," Nanomedicine, vol. 7, no. 1, pp. 107-114, 2011.

[98] H. Li, Y. Li, J. Jiao, and H. M. Hu, "Alpha-alumina nanoparticles induce efficient autophagy-dependent crosspresentation and potent antitumour response," Nature Nanotechnology, vol. 6, no. 10, pp. 645-650, 2011.

[99] H. L. Liu, Y. L. Zhang, N. Yang et al., "A functionalized singlewalled carbon nanotube-induced autophagic cell death in human lung cells through Akt-TSC2-mTOR signaling," Cell Death and Disease, vol. 19, no. 2, article e159, 2011.

[100] J. X. Yu and T. H. Li, "Distinct biological effects of different nanoparticles commonly used in cosmetics and medicine coatings," Cell \& Bioscience, vol. 19, no. 1, p. 1, 2011.

[101] M. Reale, G. Vianale, L. V. Lotti et al., "Effects of palladium nanoparticles on the cytokine release from peripheral blood mononuclear cells of palladium-sensitized women," Journal of Occupational and Environmental Medicine, vol. 53, no. 9, pp. 1054-1060, 2011.

[102] M. I. Khan, A. Mohammad, G. Patil, S.A. Naqvi, L. K. Chauhan, and I. Ahmad, "Induction of ROS, mitochondrial damage and autophagy in lung epithelial cancer cells by iron oxide nanoparticles," Biomaterials, vol. 33, no. 5, pp. 14771488, 2012.

[103] T. Sun, Y. Yan, Y. Zhao, F. Guo, and C. Jiang, "Copper oxide nanoparticles induce autophagic cell death in a549 cells," PLoS ONE, vol. 7, no. 8, Article ID e43442, 2012.

[104] T. Yokoyama, J. Tam, S. Kuroda et al., "EGFR-targeted hybrid plasmonic magnetic nanoparticles synergistically induce autophagy and apoptosis in non-small cell lung cancer cells," PLoS ONE, vol. 6, no. 11, Article ID e25507, 2011.

[105] L. Calzolai, F. Franchini, D. Gilliland, and F. Rossi, "Proteinnanoparticle interaction: identification of the ubiquitin-gold nanoparticle interaction site," Nano Letters, vol. 10, no. 8, pp. 3101-3105, 2010.

[106] H. Yamawaki and N. Iwai, "Cytotoxicity of water-soluble fullerene in vascular endothelial cells," American Journal of Physiology, vol. 290, no. 6, pp. C1495-C1502, 2006.

[107] O. Seleverstov, O. Zabirnyk, M. Zscharnack et al., "Quantum dots for human mesenchymal stem cells labeling, a sizedependent autophagy activation," Nano Letters, vol. 6, no. 12, pp. 2826-2832, 2006.

[108] Y. Chen, L. Yang, C. Feng, and L. P. Wen, "Nano neodymium oxide induces massive vacuolization and autophagic cell death in non-small cell lung cancer NCI-H460 cells," Biochemical and Biophysical Research Communications, vol. 337, no. 1, pp. 52-60, 2005. 
[109] Y. Zhang, F. Zheng, T. Yang et al., “Tuning the autophagyinducing activity of lanthanide-based nanocrystals through specific surface-coating peptides," Nature Materials, vol. 11, no. 9, pp. 817-826, 2012.

[110] P. Wei, L. Zhang, Y. Lu, N. Man, and L. Wen, "C60(Nd) nanoparticles enhance chemotherapeutic susceptibility of cancer cells by modulation of autophagy," Nanotechnology, vol. 21, no. 49, Article ID 495101, 2010.

[111] X. Ma, Y. Wu, S. Jin et al., "Gold nanoparticles induce autophagosome accumulation through size-dependent nanoparticle uptake and lysosome impairment," ACS Nano, vol. 5, no. 11, pp. 8629-8639, 2011.

[112] D. N. Johnson-Lyles, K. Peifley, S. Lockett et al., "Fullerenol cytotoxicity in kidney cells is associated with cytoskeleton disruption, autophagic vacuole accumulation, and mitochondrial dysfunction," Toxicology and Applied Pharmacology, vol. 248, no. 3, pp. 249-258, 2010.

[113] S. T. Stern and D. N. Johnson, "Role for nanomaterialautophagy interaction in neurodegenerative disease," Autophagy, vol. 4, no. 8, pp. 1097-1100, 2008.

[114] M. M. Monick, L. S. Powers, K. Walters et al., "Identification of an autophagy defect in smokers' alveolar macrophages," Journal of Immunology, vol. 185, no. 9, pp. 5425-5435, 2010.

[115] H. Afeseh Ngwa, A. Kanthasamy, Y. Gu, N. Fang, V. Anantharam, and A. G. Kanthasamy, "Manganese nanoparticle activates mitochondrial dependent apoptotic signaling and autophagy in dopaminergic neuronal cells," Toxicology and Applied Pharmacology, vol. 256, no. 3, pp. 227-240, 2011.

[116] H. L. Herd, A. Malugin, and H. Ghandehari, "Silica nanoconstruct cellular toleration threshold in vitro," Journal of Controlled Release, vol. 153, no. 1, pp. 40-48, 2011.

[117] Y. N. Wu, L. X. Yang, X. Y. Shi et al., "The selective growth inhibition of oral cancer by iron core-gold shell nanoparticles through mitochondria-mediated autophagy," Biomaterials, vol. 32, no. 20, pp. 4565-4573, 2011.

[118] H. Eidi, O. Joubert, C. Némos et al., "Drug delivery by polymeric nanoparticles induces autophagy in macrophages," International Journal of Pharmaceutics, vol. 422, no. 1-2, pp. 495-503, 2012.

[119] S. Barth, D. Glick, and K. F. Macleod, "Autophagy: assays and artifacts," Journal of Pathology, vol. 221, no. 2, pp. 117-124, 2010.

[120] O. Seleverstov, J. M. Phang, and O. Zabirnyk, "Chapter 18 semiconductor nanocrystals in autophagy research. Methodology improvement at nanosized scale," Methods in Enzymology, vol. 451, pp. 277-296, 2009.

[121] K. M. Choi, H. Y. Nam, J. H. Na et al., "A monitoring method for Atg4 activation in living cells using peptide-conjugated polymeric nanoparticles," Autophagy, vol. 7, no. 9, pp. 10521062, 2011.

[122] P. Vandenabeele, L. Galluzzi, T. Vanden Berghe, and G. Kroemer, "Molecular mechanisms of necroptosis: an ordered cellular explosion," Nature Reviews Molecular Cell Biology, vol. 11, no. 10, pp. 700-714, 2010.

[123] D. W. Zhang, J. Shao, J. Lin et al., "RIP3, an energy metabolism regulator that switches TNF-induced cell death from apoptosis to necrosis," Science, vol. 325, no. 5938, pp. 332336, 2009.

[124] J. W. Upton, W. J. Kaiser, and E. S. Mocarski, "Virus inhibition of RIP3-dependent necrosis," Cell Host and Microbe, vol. 7, no. 4, pp. 302-313, 2010.
[125] J. Hitomi, D. E. Christofferson, A. Ng et al., "Identification of a molecular signaling network that regulates a cellular necrotic cell death pathway," Cell, vol. 135, no. 7, pp. 1311-1323, 2008.

[126] W. J. Kaiser, J. W. Upton, A. B. Long et al., "RIP3 mediates the embryonic lethality of caspase-8-deficient mice," Nature, vol. 471, no. 7338, pp. 368-372, 2011.

[127] A. Oberst, C. P. Dillon, R. Weinlich et al., "Catalytic activity of the caspase-8-FLIP L complex inhibits RIPK3-dependent necrosis," Nature, vol. 471, no. 7338, pp. 363-367, 2011.

[128] H. Zhang, X. Zhou, T. McQuade, J. Li, F. K. M. Chan, and J. Zhang, "Functional complementation between FADD and RIP1 in embryos and lymphocytes," Nature, vol. 471, no. 7338, pp. 373-376, 2011.

[129] A. Degterev, Z. Huang, M. Boyce et al., "Chemical inhibitor of nonapoptotic cell death with therapeutic potential for ischemic brain injury," Nature Chemical Biology, vol. 1, no. 2, pp. 112-119, 2005.

[130] Y. H. Ma, C. P. Huang, J. S. Tsai, M. Y. Shen, Y. K. Li, and L. Y. Lin, "Water-soluble germanium nanoparticles cause necrotic cell death and the damage can be attenuated by blocking the transduction of necrotic signaling pathway," Toxicology Letters, vol. 207, no. 3, pp. 258-269, 2011.

[131] L. K. Braydich-Stolle, N. M. Schaeublin, R. C. Murdock et al., "Crystal structure mediates mode of cell death in $\mathrm{TiO}_{2}$ nanotoxicity," Journal of Nanoparticle Research, vol. 11, no. 6, pp. 1361-1374, 2009.

[132] Y. Pan, S. Neuss, A. Leifert et al., "Size-dependent cytotoxicity of gold nanoparticles," Small, vol. 3, no. 11, pp. 1941-1949, 2007.

[133] Y. Pan, A. Leifert, D. Ruau et al., "Gold nanoparticles of diameter $1.4 \mathrm{~nm}$ trigger necrosis by oxidative stress and mitochondrial damage," Small, vol. 5, no. 18, pp. 2067-2076, 2009.

[134] T. H. Kim, M. Kim, H. S. Park, U. S. Shin, M. S. Gong, and H. W. Kim, "Size-dependent cellular toxicity of silver nanoparticles," Journal of Biomedical Materials Research A, vol. 100, no. 4, pp. 1033-1043, 2012.

[135] W. K. Oh, S. Kim, O. Kwon, and J. Jang, "Shape-dependent cytotoxicity of polyaniline nanomaterials in human fibroblast cells," Journal of Nanoscience and Nanotechnology, vol. 11, no. 5, pp. 4254-4260, 2011.

[136] N. M. Schaeublin, L. K. Braydich-Stolle, A. M. Schrand et al., "Surface charge of gold nanoparticles mediates mechanism of toxicity," Nanoscale, vol. 3, no. 2, pp. 410-420, 2011.

[137] L. Harhaji, A. Isakovic, N. Raicevic et al., "Multiple mechanisms underlying the anticancer action of nanocrystalline fullerene," European Journal of Pharmacology, vol. 568, no. 13, pp. 89-98, 2007.

[138] R. Foldbjerg, P. Olesen, M. Hougaard, D. A. Dang, H. J. Hoffmann, and H. Autrup, "PVP-coated silver nanoparticles and silver ions induce reactive oxygen species, apoptosis and necrosis in THP-1 monocytes," Toxicology Letters, vol. 190, no. 2, pp. 156-162, 2009.

[139] S. Arora, J. Jain, J. M. Rajwade, and K. M. Paknikar, "Cellular responses induced by silver nanoparticles: in vitro studies," Toxicology Letters, vol. 179, no. 2, pp. 93-100, 2008.

[140] N. Asare, C. Instanes, W. J. Sandberg et al., "Cytotoxic and genotoxic effects of silver nanoparticles in testicular cells," Toxicology, vol. 291, no. 1-3, pp. 65-72, 2012.

[141] M. L. Di Giorgio, S. D. Bucchianico, A. M. Ragnelli, P. Aimola, S. Santucci, and A. Poma, "Effects of single and multi walled carbon nanotubes on macrophages: cyto and 
genotoxicity and electron microscopy," Mutation Research, vol. 722, no. 1, pp. 20-31, 2011.

[142] F. Tian, D. Cui, H. Schwarz, G. G. Estrada, and H. Kobayashi, "Cytotoxicity of single-wall carbon nanotubes on human fibroblasts," Toxicology in Vitro, vol. 20, no. 7, pp. 1202-1212, 2006.

[143] D. Cui, F. Tian, Y. Kong, I. Titushikin, and H. Gao, "Effects of single-walled carbon nanotubes on the polymerase chain reaction," Nanotechnology, vol. 15, no. 1, pp. 154-157, 2004.

[144] L. Zhu, D. W. Chang, L. Dai, and Y. Hong, "DNA damage induced by multiwalled carbon nanotubes in mouse embryonic stem cells," Nano Letters, vol. 7, no. 12, pp. 3592-3597, 2007.

[145] K. Pulskamp, S. Diabaté, and H. F. Krug, "Carbon nanotubes show no sign of acute toxicity but induce intracellular reactive oxygen species in dependence on contaminants," Toxicology Letters, vol. 168, no. 1, pp. 58-74, 2007.

[146] L. Galluzzi, L. Chiarantini, E. Pantucci et al., "Development of a multilevel approach for the evaluation of nanomaterials' toxicity," Nanomedicine, vol. 7, no. 3, pp. 393-409, 2012.

[147] M. A. Brennan and B. T. Cookson, "Salmonella induces macrophage death by caspase-1-dependent necrosis," Molecular Microbiology, vol. 38, no. 1, pp. 31-40, 2000.

[148] A. C. Reisetter, L. V. Stebounova, J. Baltrusaitis et al., "Induction of inflammasome-dependent pyroptosis by carbon black nanoparticles," Journal of Biological Chemistry, vol. 286, no. 24, pp. 21844-21852, 2011.

[149] A. S. Yazdi, G. Guarda, N. Riteau et al., "Nanoparticles activate the NLR pyrin domain containing 3 (Nlrp3) inflammasome and cause pulmonary inflammation through release of IL- $1 \alpha$ and IL- $1 \beta$," Proceedings of the National Academy of Sciences of the United States of America, vol. 107, no. 45, pp. 19449-19454, 2010.

[150] J. M. Hillegass, A. Shukla, S. A. Lathrop, M. B. MacPherson, N. K. Fukagawa, and B. T. Mossman, "Assessing nanotoxicity in cells in vitro," Wiley Interdisciplinary Reviews: Nanomedicine and Nanobiotechnology, vol. 2, no. 3, pp. 219-231, 2010.

[151] A. M. Schrand, M. F. Rahman, S. M. Hussain, J. J. Schlager, D. A. Smith, and A. F. Syed, "Metal-based nanoparticles and their toxicity assessment," Wiley Interdisciplinary Reviews: Nanomedicine and Nanobiotechnology, vol. 2, no. 5, pp. 544$568,2010$.

[152] R. Damoiseaux, S. George, M. Li et al., "No time to losehigh throughput screening to assess nanomaterial safety," Nanoscale, vol. 3, no. 4, pp. 1345-1360, 2011.

[153] S. Y. Shaw, E. C. Westly, M. J. Pittet, A. Subramanian, S. L. Schreiber, and R. Weissleder, "Perturbational profiling of nanomaterial biologic activity," Proceedings of the National Academy of Sciences of the United States of America, vol. 105, no. 21, pp. 7387-7392, 2008.

[154] L. Galluzzi, S. A. Aaronson, J. Abrams et al., "Guidelines for the use and interpretation of assays for monitoring cell death in higher eukaryotes," Cell Death and Differentiation, vol. 16, no. 8, pp. 1093-1107, 2009.

[155] B. T. Mossman, J. Bignon, M. Corn, A. Seaton, and J. B. L. Gee, "Asbestos: scientific developments and implications for public policy," Science, vol. 247, no. 4940, pp. 294-301, 1990.

[156] B. W. S. Robinson and R. A. Lake, "Advances in malignant mesothelioma," The New England Journal of Medicine, vol. 353, no. 15, pp. 1591-1603, 2005.

[157] T. Zhang, J. L. Stilwell, D. Gerion et al., "Cellular effect of high doses of silica-coated quantum dot profiled with high throughput gene expression analysis and high content cellomics measurements," Nano Letters, vol. 6, no. 4, pp. 800808, 2006.

[158] A. Zollanvari, M. J. Cunningham, U. Braga-Neto, and E. R. Dougherty, "Analysis and modeling of time-course geneexpression profiles from nanomaterial-exposed primary human epidermal keratinocytes," BMC Bioinformatics, vol. 10, supplement 11, p. S10, 2009.

[159] Y. Y. Tyurina, V. A. Tyurin, V. I. Kapralova et al., "Oxidative lipidomics of $\gamma$-radiation-induced lung injury: mass spectrometric characterization of cardiolipin and phosphatidylserine peroxidation," Radiation Research, vol. 175, no. 5, pp. 610-621, 2011.

[160] J. G. Teeguarden, B. J. Webb-Robertson, K. M. Waters et al., "Comparative proteomics and pulmonary toxicity of instilled single-walled carbon nanotubes, crocidolite asbestos, and ultrafine carbon black in mice," Toxicological Sciences, vol. 120, no. 1, pp. 123-135, 2011.

[161] Y. Zhang, Y. Xu, Z. Li et al., "Mechanistic toxicity evaluation of uncoated and PEGylated single-walled carbon nanotubes in neuronal PC12 cells," ACS Nano, vol. 5, no. 9, pp. 70207033, 2011. 

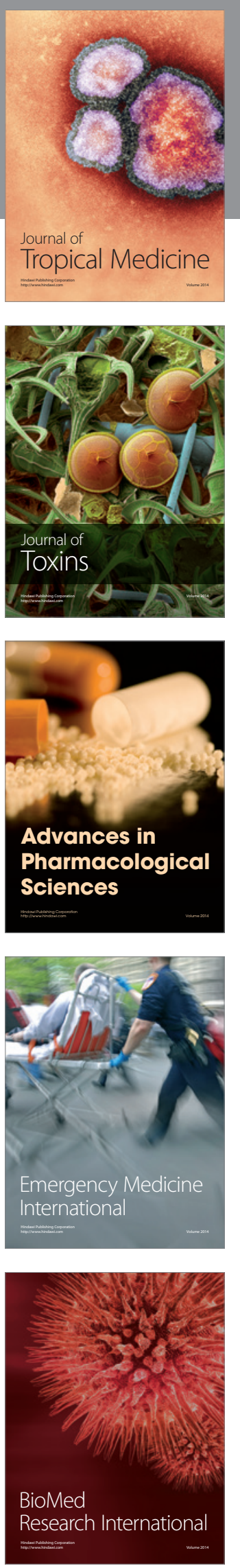
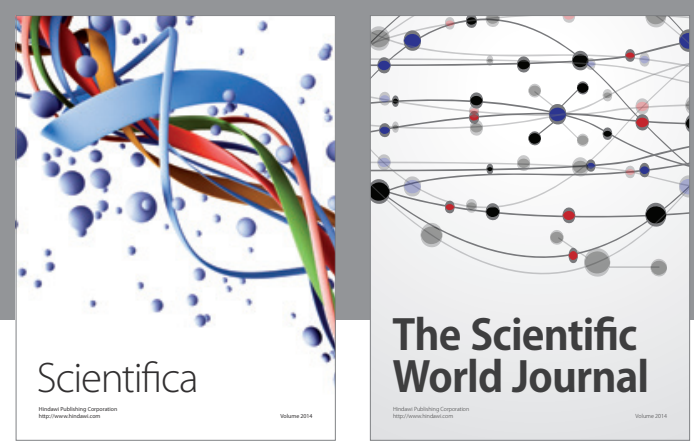

The Scientific World Journal
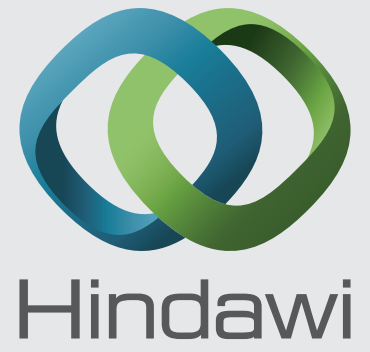

Submit your manuscripts at

http://www.hindawi.com
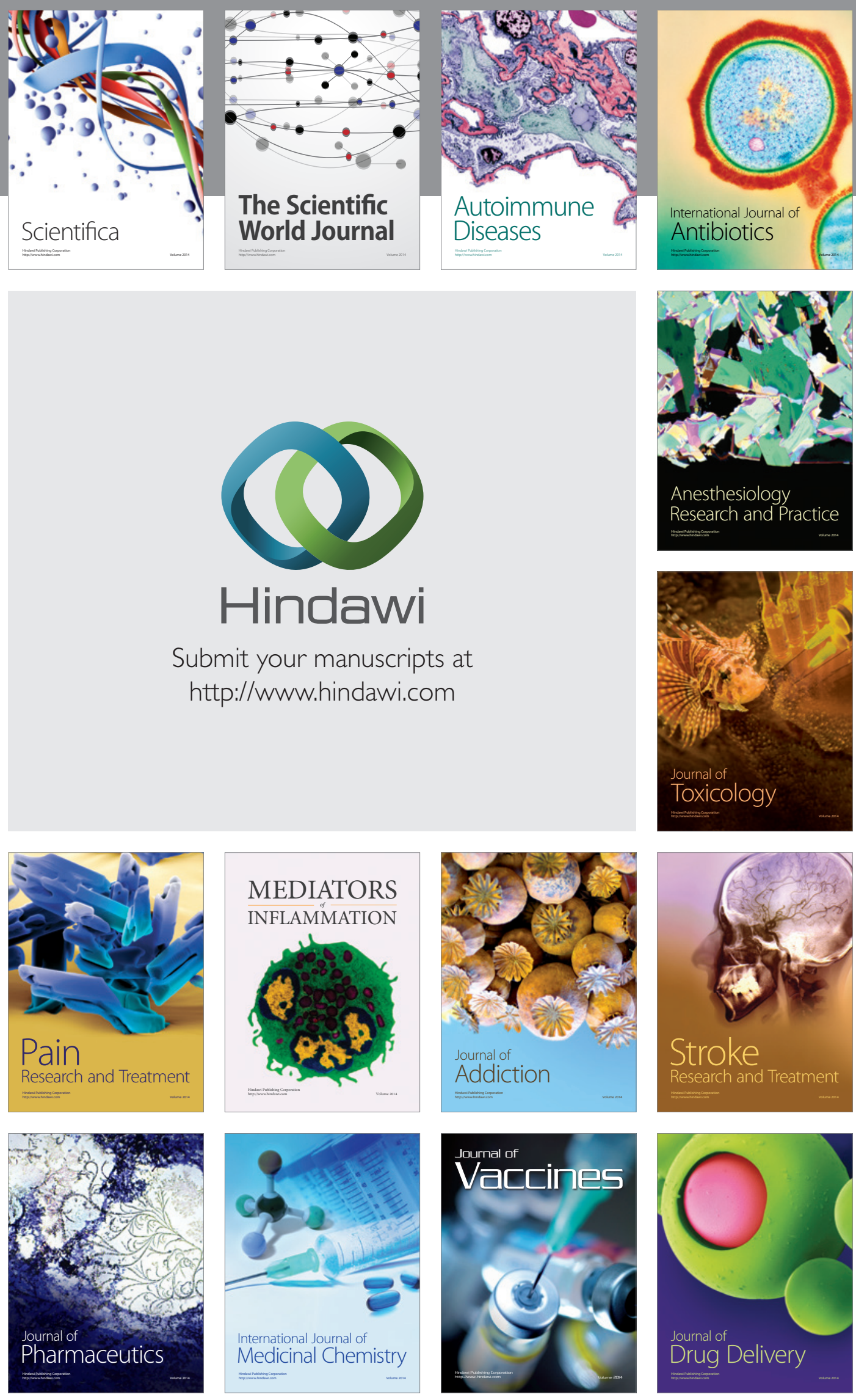